\section{Original Article}

Clinical Microbiology

Ann Lab Med 2012;32:44-49

http://dx.doi.org/10.3343/alm.2012.32.1.44

ISSN 2234-3806 elSSN 2234-3814

\title{
Evaluation of the Seeplex ${ }^{\circledR}$ Meningitis ACE Detection Kit for the Detection of 12 Common Bacterial and Viral Pathogens of Acute Meningitis
}

So Youn Shin, M.D. ${ }^{1,2}$, Kye Chul Kwon, M.D. ${ }^{1}$, Jong Woo Park, M.D. ${ }^{1}$, Ji Myung Kim, M.D. ${ }^{1}$, So Young Shin, M.D. ${ }^{3}$, and Sun Hoe Koo, M.D. ${ }^{1}$

Department of Laboratory Medicine ${ }^{1}$, College of Medicine, Chungnam National University, Daejeon; Department of Laboratory Medicine², Asan Medical Center, University of Ulsan College of Medicine, Seoul; Department of Laboratory Medicine ${ }^{3}$, College of Medicine, The Catholic University of Korea, Daejeon, Korea

Background: Bacterial meningitis is an infectious disease with high rates of mortality and high frequency of severe sequelae. Early identification of causative bacterial and viral pathogens is important for prompt and proper treatment of meningitis and for prevention of life-threatening clinical outcomes. In the present study, we evaluated the value of the Seeplex Meningitis ACE Detection kit (Seegene Inc., Korea), a newly developed multiplex PCR kit employing dual priming oligonucleotide methods, for diagnosing acute meningitis.

Methods: Analytical sensitivity of the kit was studied using reference strains for each pathogen targeted by the kit, while it's analytical specificity was studied using the human genome DNA and 58 clinically well-identified reference strains. For clinical validation experiment, we used 27 control cerebrospinal fluid (CSF) samples and 78 clinical CSF samples collected from patients at the time of diagnosis of acute meningitis.

Results: The lower detection limits ranged from $10^{1}$ copies $/ \mu \mathrm{L}$ to $5 \times 10^{1}$ copies $/ \mu \mathrm{L}$ for the 12 viral and bacterial pathogens targeted. No cross-reaction was observed. In the validation study, high detection rate of $56.4 \%$ was obtained. None of the control samples tested positive, i.e., false-positive results were absent.

Conclusions: The Seeplex Meningitis ACE Detection kit showed high sensitivity, specificity, and detection rate for the identification of pathogens in clinical CSF samples. This kit may be useful for rapid identification of important acute meningitis-causing pathogens.

Key Words: Meningitis, Multiplex PCR, Dual priming oligonucleotide
Received: July 7, 2011

Revision received: September 14, 2011

Accepted: November 1, 2011

Corresponding author: Sun Hoe Koo Department of Laboratory Medicine, Chungnam National University Hospital, 640 Daesa-dong, Jung-gu, Daejeon 301-721, Korea

Tel: $+82-42-280-7798$

Fax: +82-42-257-5365

E-mail:shkoo@cnu.ac.kr (c) The Korean Society for Laboratory Medicine. This is an Open Access article distributed under the terms of the Creative Commons Attribution Non-Commercial License (http://creativecommons.org/licenses/by-nc/3.0) which permits unrestricted non-commercial use, distribution, and reproduction in any medium, provided the original work is properly cited.

\section{INTRODUCTION}

Bacterial meningitis is an infectious disease with high rates of mortality and severe sequelae. Early identification of causative bacterial and viral pathogens is important to enable prompt and appropriate treatment and thereby prevent life-threatening clinical outcomes. Patients with suspected meningitis are generally prescribed antibiotics before hospital admission or cerebrospinal fluid (CSF) collection for examination. However, the admin- istration of antibiotics may render it difficult to culture the causative bacteria, thereby impairing microbiological diagnosis [1, 2]. To counter this problem, alternative methods of molecular identification, including 16S/23S rRNA gene amplification followed by sequencing and real-time PCR, have been developed. However, the clinical application of such techniques is limited because of the presence of interfering bacterial or viral DNA, timeconsuming nature of these assays, and small number of detection channels available on the real-time PCR platform [3-7]. 
These limitations can be overcome by the use of multiplex PCR methods, which enable the rapid and accurate identification of up to 9 bacterial and viral pathogens in clinical samples [8-10]. We evaluated the diagnostic value of the newly developed Seeplex Meningitis ACE Detection kit (Seegene Inc., Seoul, Korea), a multiplex PCR kit that uses dual priming oligonucleotide (DPO) methods. This kit detects the 12 most common bacterial and viral pathogens of acute meningitis, namely, Streptococcus pneumoniae (SP), Haemophilus influenzae (HI), Neisseria meningitidis (NM), Group B streptococci (GBS), Listeria monocytogenes (LM), herpes simplex virus (HSV)-1 and HSV-2, Varicella-Zoster virus (VZV), Epstein-Barr virus (EBV), cytomegalovirus (CMV), human herpes virus 6 (HHV-6), and human enterovirus (HEV).

\section{METHODS}

\section{Seeplex Meningitis ACE Detection kit}

The Seeplex Meningitis ACE Detection kit has 3 components: Seeplex Meningitis-B, which detects 5 bacteria (SP, HI type b, NM, GBS, and LM); Seeplex Meningitis-V1, which detects 6 viruses (HSV-1, HSV-2, VZV, EBV, CMV, and HHV-6); and Seeplex Meningitis-V2, which detects HEV. The Seeplex Meningitis-B and $\mathrm{V} 1$ assays amplify DNA, whereas the Seeplex Meningitis-V2 assay amplifies cDNA reverse-transcribed from viral RNA. The target genes amplified from the 12 strains are shown in Table 1.

\section{Multiplex PCR conditions}

Each PCR amplification was performed using $5 \mu \mathrm{L}$ of isolated nucleic acid solution, $2 \mu \mathrm{L}$ of $10 \times$ primer mixture, and $10 \mu \mathrm{L}$ of 2 $\times$ Multiplex Master Mix (Seegene Inc.) in a total volume of $20 \mu \mathrm{L}$. The amplification protocol was as follows: initial denaturation at $94^{\circ} \mathrm{C}$ for $15 \mathrm{~min}, 40$ cycles of denaturation at $94^{\circ} \mathrm{C}$ for $30 \mathrm{sec}$, annealing at $63^{\circ} \mathrm{C}$ for $90 \mathrm{sec}$, and extension at $72^{\circ} \mathrm{C}$ for $90 \mathrm{sec}$. The amplified PCR products were electrophoresed in $2 \%(\mathrm{w} / \mathrm{v})$ agarose gels and stained with ethidium bromide.

\section{Analytical sensitivity and specificity of detection}

PCR products were cloned into the vector pUC19 (size, 2,686 bp). The cloned plasmids were harvested, DNA concentrations were measured, and the numbers of target copies were calculated ( $1 \mu \mathrm{g}$ of a 1,000 -bp DNA unit equals $9.1 \times 10^{11}$ copies). The sensitivity of the system was evaluated by amplifying 10-fold serial dilutions of each plasmid (concentrations, $10^{4}$ to $10^{-1} \mathrm{cop}$ ies/20 $\mu \mathrm{L}$ ), with distilled water as the negative control. Samples were PCR-amplified and electrophoresed in $2 \%(\mathrm{w} / \mathrm{v})$ agarose gels. Analytical sensitivity was defined as the lowest template copy number for which amplified products were consistently

Table 1. Target genes used in the Seeplex Meningitis ACE Detection kit

\begin{tabular}{|c|c|c|c|c|}
\hline & Organism & Target gene & Target protein & Size of product (bp) \\
\hline Seeplex & Internal control & & & 1,000 \\
\hline \multirow[t]{5}{*}{ Meningitis-B } & SP & gyrB & DNA gyrase, subunit B & 669 \\
\hline & HI & P6 & Outer membrane protein (OMP) P6 & 532 \\
\hline & NM & ctrA & Capsule polysaccharide export outer membrane protein CtrA & 410 \\
\hline & GBS & $C f b$ & CAMP-factor (cfb) gene & 315 \\
\hline & LM & Hly & Pore-forming cytolysin listeriolysin & 213 \\
\hline Seeplex & Internal control & & & 1,000 \\
\hline \multirow[t]{7}{*}{ Meningitis-V1 } & CMV & UL54 & DNA polymerase & 590 \\
\hline & & IE & Immediate-early antigen & \\
\hline & EBV & EBNA1 & Epstein-Barr nuclear antigen1 & 400 \\
\hline & HSV-1 & UL30 & DNA polymerase catalytic subunit & 189 \\
\hline & HSV-2 & $g D$ & HSV-2 gD protein & 308 \\
\hline & VZV & ORF66 & VZV ORF66 protein & 251 \\
\hline & HHV-6 & U38 & DNA polymerase & 482 \\
\hline Seeplex & Internal control & & & 850 \\
\hline Meningitis-V2 & HEV & 5'-UTR & 5 -untranslated region & 194 \\
\hline
\end{tabular}

Abbreviations: SP, Streptococcus pneumoniae; HI, Haemophilus influenzae; NM, Neisseria meningitidis; GBS, Group B streptococcus; LM, Listeria monocytogenes; HSV-1/HSV-2, Herpes simplex virus type 1/2; VZV, Varicella-zoster virus; EBV, Epstein-Barr virus; CMV, Cytomegalovirus; HHV-6, Human herpes virus 6; HEV, Human enterovirus. 
detected in triplicate samples. The reference strains used for the 5 bacteria and 7 viruses were as follows: SP ATCC BAA255D, HI ATCC BAA-1416, NM ATCC 700532D, GBS ATCC BAA611D, LM ATCC 19114D-5, CMV ATCC VR-807, EBV Korean isolate, HSV-1 ATCC VR-260, HSV-2 ATCC VR-734, VZV Korean isolate, HHV-6 Korean isolate, and HEV ATCC VR-836/VR-784. Primer specificity was assessed by evaluating cross-reactivity with human genomic DNA and 58 reference strains, including 19 HEV species (No.12-30; Table 2).

\section{Verification using clinical CSF samples}

1) Specimen collection

Between June and November 2009, 196 clinical CSF samples were collected from 78 patients (27 women, 51 men) diagnosed with acute meningitis on the basis of clinical symptoms and CSF findings (WBC count, distribution of lymphocytes and neutrophils, and glucose level) [11, 12]. Bacterial meningitis was differentiated from viral or aseptic meningitis by a WBC count of more than $100 \mathrm{cells} / \mathrm{mm}^{3}$ with neutrophil dominance and a ratio of CSF glucose/serum glucose level of less than 0.4. Cases with insignificant WBC count or discrepant results in different parameters were classified into the undetermined group. The median patient age was $27 \mathrm{yr}$ (range, 1 month to $72 \mathrm{yr}$ ). For the verification study, we tested only the 78 samples collected at the time of diagnosis, i.e., before antibiotic therapy was initiated. Another set of 118 samples was used to assess discrepancies in positive results obtained from the same patients. Samples that were blood-colored, showed leakage, were aged over $12 \mathrm{hr}$, and strongly suspected of being contaminated (with discrepancies in the pathogens detected in consecutive tests), were excluded. All samples were assessed by conventional CSF microscopic analysis, staining, and culture.

Control CSF samples were collected from 27 patients; of these 27 patients, 5 had acute cerebral bleeding; 4, primary or metastatic brain tumors; 4, tuberculous encephalitis; 2, mumps; and 1 each, Cryptococcus neoformans infection, clinically suspected meningitis due to Candida, and rickettsia. The remaining 9 patients showed normal findings.

Table 2. Reference strains used for analysis of sensitivity and specificity of the Seeplex Meningitis ACE Detection kit

\begin{tabular}{|c|c|c|c|c|c|c|c|c|}
\hline NNo. & Organism & ATCC №. & No. & Organism & ATCC №. & №. & Organism & ATCC №. \\
\hline 0 & Human genomic DNA & & 21 & Human echovirus 6 & & 42 & N. mucosa & 25997 \\
\hline 1 & S. pneumoniae & BAA-255D & 22 & Human echovirus 7 & & 43 & N. sicca & 29256 \\
\hline 2 & H. influenzae & BAA-1416 & 23 & Human echovirus 9 & & 44 & H. ducreyi & 700724D-5 \\
\hline 3 & N. meningitidis & $700532 D$ & 24 & Human echovirus 11 & Korean isolate & 45 & H. parainfluenzae & BAA-730 \\
\hline 4 & S. agalactiae & BAA-611D & 25 & Human echovirus 25 & & 46 & L. ivanovii subsp. ivanovii & BAA-678D-5 \\
\hline 5 & L. monocytogenes & 19114D-5 & 26 & Human echovirus 30 & & 47 & L. seeligeri & $35967 D-5$ \\
\hline 6 & CMV & VR-807 & 27 & Human poliovirus 3 & & 48 & Klebsiella pneumoniae & 700721D-5 \\
\hline 7 & EBV & Korean isolate & 28 & Human echovirus 9 & VR-39 & 49 & K. oxytoca & 700324D \\
\hline 8 & HSV-1 & VR-260 & 29 & Human coxsackievirus A24 & VR-583 & 50 & Serratia marcescens & 14041 \\
\hline 9 & HSV-2 & VR-734 & 30 & Human enterovirus 70 & VR-836 & 51 & Enterobacter cloacae & 13047D-5 \\
\hline 10 & VZV & Korean isolate & 31 & S. pyogenes & $700294 D-5$ & 52 & Proteus mirabilis & $12453 D$ \\
\hline 11 & HHV-6 & Korean isolate & 32 & S. mitis & 49456D-5 & 53 & Pseudomonas aeruginosa & 47085D \\
\hline 12 & Human coxsackievirus A3 & VR-1007 & 33 & S. constellatus & 27513 & 54 & Acinetobacter baumannii & 15308 \\
\hline 13 & Human enterovirus 71 & VR-784 & 34 & S. gordonii & 51656 & 55 & Stenotrophomas Maltophilia & 13637D-5 \\
\hline 14 & Human coxsackievirus B1 & & 35 & S. oralis & 9811 & 56 & S. aureus & $700699 D-5$ \\
\hline 15 & Human coxsackievirus B2 & & 36 & S. salivarius & 9759D-5 & 57 & Enterococcus faecium & 51559D-5 \\
\hline 16 & Human coxsackievirus B3 & & 37 & S. australis & 700641 & 58 & E. faecalis & $700802 D-5$ \\
\hline 17 & Human coxsackievirus B4 & Korean isolate & 38 & S. ratti & 19645 & & & \\
\hline 18 & Human coxsackievirus B5 & & 39 & S. sobrinus & 27607 & & & \\
\hline 19 & Human coxsackievirus B6 & & 40 & S. suis & BAA-853D & & & \\
\hline 20 & Human coxsackievirus A9 & & 41 & N. gonorrhoeae & $700825 D$ & & & \\
\hline
\end{tabular}

Abbreviations: CMV, Cytomegalovirus; EBV, Epstein-Barr virus; HSV-1/HSV-2, Herpes simplex virus type 1/2; VZV, Varicella-Zoster virus; HHV-6, Human herpes virus 6 . 
2) DNA and RNA extraction

CSF specimens were centrifuged at $15,000 \times \mathrm{g}$ for $5 \mathrm{~min}$. DNA was extracted from both the supernatant and cell pellet by using a nucleic acid purification column according to the manufacturer's instructions (Qiagen Inc., Valencia, CA, USA) and used directly for Meningitis-V1 and Meningitis-B1 testing. RNA was also extracted from each CSF supernatant. cDNA was synthesized by reverse transcription using RevertAid ${ }^{\mathrm{TM}}$ First Strand cDNA Synthesis kits (Fermentas, Ontario, Canada) and used for Meningitis-V2 testing.

\section{3) Sequencing}

Positive results were confirmed by conventional PCR amplification by using single primer pairs and subsequent sequencing. Amplicons were purified by using a PCR purification kit (SolGent, Daejeon, Korea) and sequenced by using the BigDye Terminator Cycle Sequencing Kit (PE Applied Biosystems, Foster City, CA, USA) and an ABI PRISM 3730XL DNA analyzer (PE Applied Biosystems). Sequences were analyzed using the Basic Local Alignment Search Tool (BLAST) provided by The National Centre for Biotechnology Information (http://www.ncbi.nlm.nih. gov/BLAST).

\section{RESULTS}

The detection sensitivity was the highest for GBS [lower limit of detection (LoD) of 5 genomes/mL] and the lowest for $\mathrm{HI}$ (LoD of 57 genomes/mL). The LoDs for HEV, EBV, VZV, HSV-2, HHV-6, NM, CMV, SP, HSV-1, and LM were 10, 11, 11, 12, 12, 13, 16, 19,38 , and 51 genomes $/ \mathrm{mL}$, respectively. The analytical sensi- tivities for all the 12 target pathogens were higher than the 100 copies per reaction stated by the manufacturer. No cross-reaction was evident with human genomic DNA and other reference strains. The Seeplex Meningitis-V2 ACE Detection kit successfully differentiated all the $19 \mathrm{HEV}$ species from the other strains.

CSF samples were obtained from 78 patients at the time of diagnosis of active meningitis and before administration of antibiotic treatment. Among these samples, 44 (56.4\%) yielded positive results with the Seeplex kit (Table 3). Five cases (6.4\%) showed positive results for HEV (4) and HSV-1 (1), which were consistent with the results of conventional studies. However, in 2 cases the results were not consistent with the results of conventional studies. One was positive for both $L M$ and EBV in Seeplex Meningitis ACE detection kit, but positive only for LM in the conventional study; the other tested positive for HEV in Seeplex Meningitis ACE detection kit but positive for VZV in the conventional study. Each case presented a bacterial and a viral features, respectively in CSF analysis.

The Seeplex Meningitis ACE detection kit detected causative pathogens for 37 cases (47.4\%) that tested negative in the conventional studies. Two patients had single bacterial infection with GBS and LM, and CSF analysis revealed bacterial and undetermined features, respectively. Single viral infections were evident in 16 patients with HEV, 9 with VZV, 3 with HSV-1, and 1 each with HSV-2 and EBV. All the cases with positive results for viruses showed viral or undetermined features in CSF analysis. Five patients showed simultaneous infection with 2 bacterial or viral pathogens: 2 tested positive for both SP and HEV and 1 each tested positive for SP and HSV-1, SP and VZV, and EBV and HSV-1. One of the cases positive for both SP and HEV had

Table 3. Distribution of strains detected by Seeplex Meningitis ACE Detection kit and comparison to conventional study results

\begin{tabular}{|c|c|c|c|c|c|c|c|c|c|c|}
\hline \multirow{3}{*}{$\begin{array}{l}\text { Seeplex Meningitis } \\
\text { ACE detection kit } \\
\begin{array}{l}\text { Conventional study } \\
\text { Interpretation }\end{array}\end{array}$} & \multicolumn{5}{|c|}{ Positive } & \multicolumn{5}{|c|}{ Negative } \\
\hline & \multicolumn{2}{|r|}{ Positive } & \multicolumn{3}{|c|}{ Negative } & \multicolumn{2}{|c|}{ Positive } & \multicolumn{3}{|c|}{ Negative } \\
\hline & Concordant & Discordant* & Bacterial & Viral & Co-infection & Bacterial & Viral & Bacterial & Viral & Undetermined \\
\hline \multirow{6}{*}{$\mathrm{N}$} & 5 & 2 & 2 & 30 & 5 & 1 & 4 & 6 & 13 & 10 \\
\hline & HEV (4) & LM/EBV (S), LM (C) (1); & GBS (1) & HEV (16) & $\mathrm{SP}+\mathrm{HEV}(2)$ & $\mathrm{SP}(1)$ & $\mathrm{EBV}(1)$ & & & \\
\hline & HSV-1 (1) & HEV (S), VZV (C) (1) & LM (1) & VZV (9) & $S P+H S V-1(1)$ & & VZV (1) & & & \\
\hline & & & & HSV-1 (3) & $S P+V Z V(1)$ & & HEV (1) & & & \\
\hline & & & & HSV-2 (1) & EBV + HSV-1 (1) & & HSV-1 (1) & & & \\
\hline & & & & EBV (1) & & & & & & \\
\hline
\end{tabular}

*Discordant cases consist of a case that was positive for both LM and EBV when tested with the Seeplex Meningitis ACE detection kit (S) but positive for only LM in the conventional test (C), and the other case was positive for HEV in Seeplex Meningitis ACE detection kit (S), but positive for VZV in the conventional test (C).

Abbreviations: HEV, Human enterovirus; LM, Listeria monocytogenes; EBV, Epstein-Barr virus; GBS, Group B streptococcus; SP, Streptococcus pneumoniae; HSV-1, Herpes simplex virus type 1; VZV, Varicella-zoster virus; HSV-2, Herpes simplex virus type 2. 
CSF findings compatible with bacterial meningitis, while the others had features consistent of viral meningitis, with lymphocyte dominance and high glucose level. Sequencing of amplicons showed no evidence of false-positive cross-reactivity; the rates of BLAST match were $98-100 \%$.

CSF samples obtained from the remaining 34 patients did not test positive with the Seeplex kit. Sequential work-up with conventional studies showed that 1 patient each was infected with EBV, VZV, SP, HEV, and HSV-1 and had consistent CSF findings. The pathogenic agents in the other 29 patients could not be identified, although CSF analysis indicated that 6 had bacterial infection, 13 had viral infection, and the remaining 10 had indeterminate findings. None of the control cases showed false-positive results.

\section{DISCUSSION}

Acute meningitis requires prompt treatment to avoid life-threatening clinical outcomes and severe sequelae. Since various viral and bacterial pathogens can cause acute meningitis, the causative agent must be identified before treatment is initiated. Conventional diagnostic tools, including CSF staining, culture, and antigen analysis, have limited diagnostic sensitivity and specificity. This has prompted the development of several molecular methods employing conventional, real-time, or multiplex PCR. Although previously developed multiplex PCR methods can rapidly identify up to 9 bacterial and viral agents, the Seeplex Meningitis ACE detection kit, which employs a DPO method, can identify the 12 most common bacterial and viral agents that cause meningitis: SP, HI, NM, GBS, LM, CMV, HEV, EBV, HSV-1, HSV2, HHV-6, and VZV. DPOs, which consist of 2 separate priming regions joined by a polydeoxyinosine linker, yield 2 primer segments with distinct annealing properties. The long $5^{\prime}$-segment initiates stable priming, whereas the short $3^{\prime}$-segment controls target-specific extension; the use of these 2 primer segments effectively eliminates non-specific priming and yields consistently high PCR specificity even under less-than-optimal PCR conditions [13]. This method is highly appropriate for the identification and differentiation of viral and bacterial pathogens with very variable genetic characteristics and low availability of primer sites. Several multiplex PCR kits using the DPO technology have been developed to identify common viral and bacterial pathogens causing respiratory infections and diarrhea, and such kits are currently being used in clinical laboratories [14-16].

We found that the Seeplex Meningitis ACE Detection kit offered high sensitivity and specificity for identifying bacterial and viral pathogens in patients diagnosed with acute meningitis. The LoDs for the 12 pathogens ranged from 10-50 copies/ $\mu \mathrm{L}$, and no cross-reaction with human genomic DNA or reference (clinically identified) bacterial and viral pathogens was evident, indicating the high specificity of the kit.

Our validation study revealed that the kit successfully identified pathogens in the CSF samples collected from 44 of the 78 (56.4\%) patients who were clinically diagnosed with acute meningitis. Only 6 of the 44 pathogens identified using the Seeplex Meningitis ACE Detection kit were also identified by other laboratory methods, with the pathogen being HEV in 4 cases and HSV-1 and LM in the remaining 2 cases. Six CSF samples were simultaneously positive for 2 pathogens, suggesting co-infection or contamination rather than false-positivity, because subsequent sequencing of PCR products yielded 98-100\% matches with sequences in the BLAST database. Of the 12 pathogens assayed, HEV had the highest prevalence and was detected in 23 samples by the Seeplex Meningitis ACE Detection kit. Of the bacterial strains, SP was the most frequently detected; SP was detected in 5 samples, although it was detected along with viruses, including HEV, HSV-1, and VZV, in 4 samples.

Five of the 34 patients, whose samples were negative at the time of diagnosis were later found to have EBV, VZV, SP, HEV, and HSV-1 infection when investigated by conventional studies. These discrepancies were perhaps attributable to inter-specimen differences at varying stages of infection. Of the other 29 patients who tested negative for all pathogens, 10 had indeterminate CSF parameters, whereas 19 showed findings consistent with bacterial or viral infection. The presence of clinical features of meningitis and indeterminate CSF findings in the 10 patients may be attributed to conditions other than acute viral or bacterial meningitis. In contrast, meningitis in the 19 patients with CSF findings consistent with bacterial or viral infections may have been caused by pathogens other than the 12 assayed by the Seeplex Meningitis ACE Detection kit. Alternatively, the concentration of pathogens in the CSF may have been too low to permit detection.

In conclusion, the Seeplex Meningitis ACE Detection kit showed high sensitivity and specificity for the 12 most common bacterial and viral agents causing acute meningitis. A high detection rate was observed in the CSF samples obtained from patients clinically diagnosed with acute meningitis. This kit may enable the rapid identification of pathogens in patients with acute meningitis. 
Shin SY, et al.

Twelve-plex PCR for acute meningitis

ANNALS OF

LABORATORY

MEDICINE

\section{Authors' Disclosures of Potential Conflicts of Interest}

No potential conflict of interest relevant to this article was reported.

\section{REFERENCES}

1. Grimwood K, Anderson P, Anderson V, Tan L, Nolan T. Twelve year outcomes following bacterial meningitis: further evidence for persisting effects. Arch Dis Child 2000;83:111-6.

2. Weisfelt M, van de Beek D, Spanjaard L, Reitsma JB, de Gans J. Clinical features, complications, and outcome in adults with pneumococcal meningitis: a prospective case series. Lancet Neurol 2006;5:123-9.

3. Bäckman A, Lantz P, Rådström P, Olcén P. Evaluation of an extended diagnostic PCR assay for detection and verification of the common causes of bacterial meningitis in CSF and other biological samples. Mol Cell Probes 1999;13:49-60.

4. Schuurman T, de Boer RF, Kooistra-Smid AM, van Zwet AA. Prospective study of use of PCR amplification and sequencing of $16 \mathrm{~S}$ ribosomal DNA from cerebrospinal fluid for diagnosis of bacterial meningitis in a clinical setting. J Clin Microbiol 2004;42:734-40.

5. Welinder-Olsson C, Dotevall L, Hogevik H, Jungnelius R, Trollfors B, Wahl $\mathrm{M}$, et al. Comparison of broad-range bacterial PCR and culture of cerebrospinal fluid for diagnosis of community-acquired bacterial meningitis. Clin Microbiol Infect 2007;13:879-86.

6. Clarke SC. Detection of Neisseria meningitidis, Streptococcus pneumoniae, and Haemophilus influenzae in blood and cerebrospinal fluid using fluorescence-based PCR. Methods Mol Biol 2006;345:69-77.
7. Smith K, Diggle MA, Clarke SC. Automation of a fluorescence-based multiplex PCR for the laboratory confirmation of common bacterial pathogens. J Med Microbiol 2004;53:115-7.

8. Bøving MK, Pedersen LN, Møller JK. Eight-plex PCR and liquid-array detection of bacterial and viral pathogens in cerebrospinal fluid from patients with suspected meningitis. J Clin Microbiol 2009;47:908-13.

9. Ren HY, An SY, Li MC. Detection of bacterial meningitis by multiplex polymerase chain reaction. Zhongguo Yi Miao He Mian Yi 2010;16:47-51.

10. Uzuka R, Kawashima H, Hasegawa D, loi H, Amaha M, Kashiwagi Y, et al. Rapid diagnosis of bacterial meningitis by using multiplex PCR and real time PCR. Pediatr Int 2004;46:551-4.

11. Chang WN, Lu CH, Huang CR, Tsai NW, Chuang YC, Chang CC, et al. Changing epidemiology of adult bacterial meningitis in southern taiwan: a hospital-based study. Infection 2008;36:15-22.

12. Thwaites GE, Chau TT, Stepniewska K, Phu NH, Chuong LV, Sinh DX, et al. Diagnosis of adult tuberculous meningitis by use of clinical and laboratory features. Lancet 2002;360:1287-92.

13. Chun JY, Kim KJ, Hwang IT, Kim YJ, Lee DH, Lee IK, et al. Dual priming oligonucleotide system for the multiplex detection of respiratory viruses and SNP genotyping of CYP2C19 gene. Nucleic Acids Res 2007;35:e40.

14. Sung H, Park SJ, Woo YD, Choi BH, Kim MN. Evaluation of Seeplex RV detection kit for detecting rhinovirus, human metapneumovirus, and coronavirus. Korean J Lab Med 2008;28:109-17.

15. Park J, Kim JK, Rheem I, Kim J. Evaluation of Seeplex Pneumobacter multiplex PCR kit for the detection of respiratory bacterial pathogens in pediatric patients. Korean J Lab Med 2009;29:307-13.

16. Higgins RR, Beniprashad M, Cardona M, Masney S, Low DE, Gubbay JB. Evaluation and verification of the Seeplex Diarrhea-V ACE assay for simultaneous detection of adenovirus, rotavirus and norovirus genogroups I and II in clinical stool specimens. J Clin Microbiol 2011;49: 3154-62. 